\title{
O PÚBLICO: CONSUMIDORES E CIDADÃOS? INICIATIVAS DE PARTICIPAÇÃO E A REFORMA DA REGULAÇÃO DO SERViço PÚblico de média na Alemanha
}

\author{
Christine Horz
}

\begin{abstract}
Resumo
O tratado federal inter-estados da Alemanha e a estrutura regulatória do serviço público de média (SPM) foram recentemente alvo de reformas. O ponto de partida deste processo foi a chamada decisão ZDF, tomada pelo Tribunal Constitucional Federal em 25 de março de 2014'. O Tribunal Constitucional Federal foi confrontado com uma avaliação da constitucionalidade da composição do conselho de radiodifusão da segunda maior empresa de televisão do país, a ZDF (Zweites Deutsches Fernsehen). O processo desencadeado resultou numa série de reformas em regimes regulatórios de vários estados da federação. Este artigo compara os processos de decisão relativos aos dois maiores operadores de serviço público no país: a WDR (Westdeutscher Rundfunk), legislativamente dependente da região Renânia do Norte-Westefalia, e a ZDF, legislativamente dependente da região Renânia-Palatinado. No caso destes dois estados federais alemães, este trabalho faz uma análise das estratégias adoptadas pelas chancelarias, as autoridades legislativas responsáveis, na negociação de um novo enquadramento regulatório. O trabalho discute ainda o tema da 'audiência presumida' durante as negociações e a efectiva participação da sociedade civil nos debates sobre governaçção e políticas dos média. A análise baseia-se numa sistematização em torno do cidadão e do consumidor em políticas mediáticas. A hipótese de trabalho assume que a imagem presumida sobre a audiência é diferente nos dois estados. As negociações no estado Renânia-Palatinado podem ser descritas como ambivalentes em termos da sua percepção sobre a audiência ao passo que o processo no estado de Renânia do Norte-Westefália tratou a audiência com um olhar centrado na cidadania. $O$ estudo sugere que a decisão ZDF criou uma dinâmica de debate mais alargada sobre as políticas para os média na Alemanha, um tema até então negligenciado tanto em termos de sociedade civil, como de regulação e de estudos de comunicação.
\end{abstract}

\section{Palavras-chave}

Política dos media; regulação dos media; participação cívica; serviço público de média; Alemanha

\section{INTRODUÇÃO}

O Serviço Público de Radiodifusão da Alemanha foi criado pelas forças aliadas na sequência da Segunda Guerra Mundial. Na República Federal Alemã do Ocidente seguiu o modelo britânico de uma entidade financiada por uma taxa audiovisual com um mandato de serviço à comunidade. Em reação à Era Nazi, em que os média audiovisuais foram usados como ferramenta de propaganda, o serviço público de radiodifusão da nova república foi organizado com uma relativa independência da intervenção

\footnotetext{
' Zweites Deutsches Fernsehen (ZDF; Segunda Televisão Alemã) é a segunda maior estação de TV do país e tem sede em Mainz, na região Renânia-Palatinado.
} 
estatal, garantida na Constituição². Seguindo os planos da britânica BBC, a regulação do Serviço Público de Radiodifusão na Alemanha foi organizada em torno de um modelo híbrido, entre Estado e mercado, adoptando mecanismos de co-regulação específicos a cada entidade (enquanto alternativa a modelos de controlo estatal ou de completa auto-regulação). Os conselhos de radiodifusão garantem o cumprimento de padrões de transmissão e elegem a direção da empresa, enquanto que as administrações de radiodifusão atuam em questões de financiamento e de pessoal. Ambas as entidades seguem um modelo de representação democrática. Até meados de 2016 os membros do conselho eram exclusivamente representantes de "grupos sociais relevantes", como partidos políticos e organizações derivadas, associações de empregadores, organizações de funcionários e sindicatos, igrejas e instituições educativas. Cada representante tinha, em todo o caso, um mandato para representar o público em geral e não a sua organização específica. Para além deste processo, nenhuma outra forma de participação na governança dos média era permitida à sociedade civil.

Em 2009 o Tribunal Constitucional Federal foi confrontado com a questão de saber se a composição dos conselhos no serviço público de média e a forte influência política no seu funcionamento estariam em conformidade com o texto fundamental ${ }^{3}$. O Tribunal Constitucional Federal decidiu em favor da queixa e emitiu um pronunciamento onde se dizia que a composição do conselho de radiodifusão do segundo maior operador de serviço público - a ZDF - violava o princípio constitucional da liberdade de influência estatal. A decisão tornou-se vinculativa não apenas para a ZDF mas também para 11 outras estações federais de serviço público na Alemanha (Dörr, 2014, p. 6). O tribunal pediu aos legisladores a preparação de um projeto para um novo enquadramento regulatório até junho de 2015. A chancelaria do estado Renânia-Palatinado assumiu a gestão do processo de negociação, uma vez que a ZDF tem sede em Mainz, naquela região. Como a ZDF tem uma abrangência nacional, todos os primeiro-ministros dos 16 estados da federação tiveram que concordar com a proposta de um novo enquadramento legal para o funcionamento dos órgãos de decisão da entidade. As negociações oficiais tiveram lugar entre o momento da decisão do tribunal, em março de 2014, e a apresentação da versão provisória do novo texto pelos 16 primeiro-ministro, dentro do prazo inicialmente estabelecido. Foram acompanhadas por um período de consulta pública durante o qual indivíduos e grupos de interesse submeteram declarações por escrito. Em 14 de junho de 2014 os primeiro-ministros de todos os estados federais propuseram um novo enquadramento regulatório 4 e os 16 parlamentos federais aprovaram $017^{\circ}$ tratado de radiodifusão inter-estadual ZDF.

\footnotetext{
${ }^{2}$ Na Alemanha, a Constituição tem o nome de Lei Básica. Em 1949 as forças aliadas elegeram um conselho de especialistas para desenhar o novo texto constitucional. Não foi, por isso, escolhido de forma pública pelos cidadãos, numa altura em que a Democracia tinha ainda uma nova existência frágil.

${ }^{3}$ A expressão comum Serviço Público de Radiodifusão pode ser substituída por Serviço Público de Média em virtude da estratégia multiplataforma num ambiente digital de rede (Enli, 2008).

${ }^{4}$ A ZDF é uma empresa de âmbito nacional, ao contrário das estações sob a influência da ARD. É regulada por um tratado interestadual assinado pelos chefes de governo de todos os estados. Em contraste, o tratado WDR é adoptado pelo parlamento federal de Renânia do Norte-Westfalia, uma vez que se trata de um empresa de âmbito regional.
} 
Dando seguimento ao veredito do Tribunal Constitucional Federal, foram também escrutinados os órgãos de supervisão da emissora da Alemanha ocidental, a WDR (Westdeutscher Rundfunk) - a maior estação emissora sob a alçada do Grupo de Trabalho para emissoras de serviço público na República Federal da Alemanha, a ARD (Arbeitsgemeinschaft der öffentlich-rechtlichen Rundfunkanstalten der Bundesrepublik Deutschland). Depois de um processo aberto de consultas o tratado WDR foi adoptado em 2 de fevereiro de 2016, estando ainda por avaliar o reflexo do contributo dos cidadãos nas alterações assumidas.

Este estudo foi elaborado com base em relatórios, notas de imprensa e observações e, numa primeira parte, discute um enquadramento conceptual sobre a possibilidade de as audiências serem apresentadas enquanto actores da sociedade civil ou enquanto consumidores. Com base neste território teórico a análise desenvolve-se em torno do conceito de "audiência implícita". A segunda parte analisa em detalhe os dois processo negociais para novos enquadramentos regulatórios na regiões Renânia-Palatinado (onde se encontra a sede da ZDF) e Renânia do Norte-Westefália (onde se localiza a WDR). O foco da análise é o nível de participação cidadã possível em cada um dos processos. O trabalho pretende, assim, contribuir para um crescente corpo de literatura interligando áreas distintas de observação, como os estudos de audiências e as políticas para os média (Daskal, 2016; Livingstone \& Lunt, 2011). Na terceira parte do trabalho apresentam-se as conclusões.

\section{CONSIDERAÇÕES SOBRE O PAPEL DAS AUDIÊNCIAS ENQUANTO AGENTES DA SOCIEDADE CIVIL E ESPAÇOS DE CIDADANIA}

Segundo Livingstone e Lunt (2011), a regulação dos média é determinada por imagens específicas sobre a audiência. Os autores avançam o conceito de "audiência implícita" e identificam duas visões distintas - consumidores e cidadãos. O estudo da regulação dos média no Reino Unido deixa claro que as entidades responsáveis, alinhadas com a indústria, tendem a centrar-se nas escolhas dos consumidores em vez dos interesses dos cidadãos os dos direitos da Comunicação. Como consequência, os consumidores adquirem o direito de reclamar, mas não o direito de participar.

O paradigma dominante nos estudos de audiência adere genericamente a visões dos usuários como consumidores (cujas escolhas mediáticas correspondem a gratificações individuais), como vítimas (que necessitam de ser protegidos da influência dos média) ou como unidades de valor (às quais corresponde uma quantia concreta que a indústria publicitária está disposta a pagar pela sua atenção) (Webster \& Phalen, 1996). A qualidade dos média é, na maior parte destas leituras, ligada diretamente às escolhas dos consumidores. Porém, os interesses dos consumidores não são sempre congruentes com os critérios de qualidade definidos por valores normativos. Em conformidade, "alguns estudos demonstram que conteúdos mediáticos classificados como sendo de 'alta qualidade' numa perspectiva normativa não atingem valores significativos em termos de indicadores de audiência" (Hasebrink, 2011, p. 323). 
Uma razão pela qual não foi ainda suficientemente conceptualizado e investigado o papel do usuário-cidadão numa sociedade democrática será, precisamente, esta contradição entre os papéis que lhe são atribuídos (Hasebrink \& Schmidt, 2012). Assume, por isso, maior relevância a sua integração nos processos de desenvolvimento de políticas para os média e regulação, uma vez que aí se articulam critérios normativos de qualidade, como a diversidade, a isenção informativa, a necessidade de um jornalismo crítico e de investigação e a credibilidade. Ao contrário dos consumidores, os cidadãos podem já ter interesse nos média como uma área vital da sociedade em que, por exemplo, se abre a possibilidade de um melhor entendimento de todos os seus membros e problemas (Hasebrink, 2011, p. 325). Estes objetivos normativos estão diretamente ligados ao funcionamento de uma sociedade civil.

Na perspectiva da teoria democrática, o processo de deliberação assenta num diálogo público sobre opções políticas no qual, idealmente, todos os segmentos da sociedade são incluídos e podem participar; isto inclui até os menos organizados, para além do Estado e dos interesses do mercado, a chamada sociedade civil (Habermas 1990). A participação desta sociedade civil numa esfera pública aberta é mesmo apresentada como um valor central dos sistemas democráticos. A sociedade civil é definida por funções com uma conotação positiva - grupos ou mesmo cidadãos a título individual tentam ter uma voz pública ao serviço do bem comum com impacto na formação de opinião e nos processos de decisão. À sociedade civil é ainda atribuída uma característica relevante, a da 'sensibilidade aos problemas', em resultado da sua proximidade à vida diária do cidadão comum e do seu afastamento relativamente a lógicas de conquista ou de manutenção de poder. Por contraponto, é também caracterizada por baixos níveis de organização e por uma fraca contribuição para os processos legislativos, tornando-a numa parceira frágil dos debates institucionalizados sobre os média. A audiência enquanto cidadã "é, neste enquadramento, um típico ator de sociedade civil" (Hasebrink, 2011, p. 329)

Este questionamento pode ser alargado a leituras da área dos estudos de Comunicação que se centram na extensão da regulação dos média e da sua governança (Kleinsteuber, 2011; Krotz, 1996; Weichert, 2005). Algumas delas, influenciadas pela ciência política e por uma postura favorável a uma maior visibilidade, defendem a impossibilidade de tomar decisões neste domínio sem participação cívica (Kleinsteuber, 2011, pp. 68-69). Sobretudo num contexto de grande competitividade no sector dos média a necessidade de uma governança mais participada das entidades prestadoras de serviço público é acrescida; pode assumir-se que um serviço público de média "será ainda mais relevante na era do digital" para servir de contraponto à influência comercial e para manter padrões de qualidade na produção (Jakubowicz, 2010, p. 11). "A relevância para o processo democrático e para o discurso político é acrescida" sempre que os prestadores de serviço público conseguem distinguir-se num sistema político específico e operam, dessa forma, também como equilibradores da pressão para uma internacionalização dos mercados (Jakubowicz, 2010, p. 11). Isto passa por uma 'extensão horizontal' das políticas de média, ou seja, pela abertura de mais espaços à participação da audiência enquanto cidadã nos processos de governança e de regulação (Foster 2007; Jarren, 2007; Puppis, 
d'Haenens \& Saeys, 2007). O objetivo final será o de proporcionar à audiência não apenas o acesso pelo a direitos mas também a assumpção de responsabilidades por forma a garantir uma maior legitimidade das decisões programáticas e estratégicas. A Literacia Mediática é entendida como uma ante-câmara da participação cidadã nestes processos de decisão (Jarren, 2007).

Em relação ao acima mencionado papel do audiência cidadã, pode supor-se que as oportunidades comunicativas existentes de média participativos, ou aplicações Web 2.0, respectivamente, aumentam a acessibilidade da sociedade civil ao discurso e, como tal, tornam mais fácil o envolvimento no debate público sobre política e regulação dos meios de comunicação. No entanto, no que diz respeito aos ativistas nos debates sobre políticas de média, a expectativas elevadas correspondem resultados desanimadores: a maioria dos ativistas da sociedade civil nos novos média parece estar mais preocupada com a participação em debates sobre crítica dos média do que em discussões sobre política mediática (Eilders, 2011, p. 176). Além disso, a audiência parece preferir aderir às "rotas controladas do atendimento ao cliente e das reclamações" (Livingstone \& Lunt, 2011, p. 173). Estes resultados parecem reforçar a 'imagem implícita' dos reguladores de uma audiência enquanto consumidora em vez de cidadã; a audiência parece aceitar o seu papel de consumidora e tem dificuldades em se identificar num outro, especialmente quando se trata de participar em debates sobre políticas dos média. Os reguladores não parecem estar muito interessados numa mudança dessa relação hierárquica e, consequentemente, fala-se mais 'em nome' da audiência do que se deixa ouvir a sua voz.

Leituras críticas questionam se a participação discursiva consegue satisfazer plenamente os princípios democráticos e enunciam hierarquias de poder existentes nos debates públicos e nos processos de tomada de decisão. Nico Carpentier, por exemplo, defende um 'modelo maximalista' de participação, no qual não só seja possível tomar parte em debates ou eleições, mas também tomar decisões nas instituições de média e na sua regulação. Pede, por isso, "relações de poder equalizadas entre atores privilegiados e não privilegiados em determinados processos decisórios" (Carpentier, 2015, p. 20).

É importante o acesso ao debate e à interacção com os organismos de radiodifusão através de rotinas controladas. Mas só se poderá falar de efetiva participação se a audiência cidadã tiver acesso a um envolvimento pleno nos processo de tomada de decisão. Como os serviços públicos de média são entendidos como instituições sociais a audiência (ou melhor, a sociedade civil como participante no debate público num plano intermédio entre o Estado e o mercado) deveria ser incluída na formulação e regulação das políticas de média. Esta participação na governação dos meios de comunicação social amplia, por sua vez, a promoção da cidadania e deve, portanto, ser vista como uma parte vital da finalidade dos serviços públicos de média (EBU, 2014).

\section{OperacionalizaÇÃo}

Os estudos e abordagens acima mencionados podem ser condensados numa sistematização genérica que se apresenta como um passo em diante na definição da 
audiência enquanto cidadã, mas que está longe de pretender fornecer uma visão completa das abordagens relacionadas com a participação dos usuários nas políticas de média. Um tema tão complexo necessita forçosamente do contributo de mais investigações empíricas (Ver Tabela 1).

\begin{tabular}{|c|c|c|c|c|}
\hline AUtOR(ES) & Perspectiva & $\begin{array}{l}\text { ARGUMENTOS/No- } \\
\text { TAS CRÍTICAS }\end{array}$ & AUDIÊNCIA IMPLÍCITA & OBJETIVOS NORMATIVOS \\
\hline $\begin{array}{l}\text { Livingstone \& } \\
\text { Lunt (2011); } \\
\text { Hasebrink } \\
\text { (2011) }\end{array}$ & $\begin{array}{l}\text { Estudos críticos } \\
\text { de Audiência; } \\
\text { intersecção } \\
\text { entre estudos } \\
\text { de Audiência } \\
\text { e de Política }\end{array}$ & $\begin{array}{l}\text { Estudos de audiência } \\
\text { centrados no consumidor e } \\
\text { em políticas para os média; } \\
\text { papéis indiferenciados para } \\
\text { a audiência; o consumidor } \\
\text { procura apenas gratificação } \\
\text { pessoal e é vulnerável e } \\
\text { vitimizado. Os direitos dos } \\
\text { cidadãos não negligen- } \\
\text { ciados ou apresentados } \\
\text { de forma ambivalente. } \\
\text { O foca da atenção é a } \\
\text { regulação do mercado. }\end{array}$ & $\begin{array}{l}\text { A audiência enquanto } \\
\text { grupo de consu- } \\
\text { midores, vítima ou } \\
\text { bem transaccionável; } \\
\text { olhar 'de cima para } \\
\text { baixo'; a literacia } \\
\text { mediática entendida } \\
\text { como conhecimento } \\
\text { para o consumidor. }\end{array}$ & $\begin{array}{l}\text { Foco da investigação e da } \\
\text { política num interesse dos } \\
\text { cidadãos nos média que } \\
\text { responda a valores demo- } \\
\text { cráticos, sociais e culturais; } \\
\text { direitos da comunicação; re- } \\
\text { des inclusivas, interligadas e } \\
\text { sobrepostas de participação. }\end{array}$ \\
\hline $\begin{array}{l}\text { Puppis \& } \\
\text { D‘Haenens } \\
\text { (2007), Kleins- } \\
\text { teuber (2011); } \\
\text { Jarren (2007) }\end{array}$ & $\begin{array}{l}\text { Governança } \\
\text { dos média }\end{array}$ & $\begin{array}{l}\text { Extensão horizontal e } \\
\text { vertical do governo; incluir } \\
\text { os cidadãos na regulação } \\
\text { dos média é necessário para } \\
\text { alcançar decisões estáveis. }\end{array}$ & $\begin{array}{l}\text { Cidadão; cidadão } \\
\text { como ator não- } \\
\text {-governamental no } \\
\text { processo de decisão. }\end{array}$ & $\begin{array}{l}\text { Governança dos média } \\
\text { como uma nova forma de } \\
\text { legitimar as políticas para } \\
\text { os média, co-responsabi- } \\
\text { lizando os cidadãos pela } \\
\text { salvaguarda do pluralismo } \\
\text { e da qualidade dos média. }\end{array}$ \\
\hline $\begin{array}{l}\text { Habermas } \\
\text { (1990) }\end{array}$ & $\begin{array}{l}\text { Esfera Pública; } \\
\text { Teoria deliberativa } \\
\text { / Participativa }\end{array}$ & $\begin{array}{l}\text { A Esfera Pública é dominada } \\
\text { por grupos influentes e pal } \\
\text { indústria dos média; os } \\
\text { cidadãos são negligenciados } \\
\text { nos debates públicos em- } \\
\text { bora a sociedade civil seja } \\
\text { 'sensível aos problemas'. }\end{array}$ & $\begin{array}{l}\text { Cidadão; a participa- } \\
\text { ção no debate público } \\
\text { reforça a cidadania e } \\
\text { legitima a democracia. }\end{array}$ & $\begin{array}{l}\text { A sociedade civil deve- } \\
\text { ria poder participar no } \\
\text { debate público; o acesso } \\
\text { deveria ser aberto a todos } \\
\text { os membros da sociedade. }\end{array}$ \\
\hline $\begin{array}{l}\text { Carpentier } \\
(2011)\end{array}$ & $\begin{array}{l}\text { Democracia } \\
\text { radical }\end{array}$ & $\begin{array}{l}\text { Todas as instituições } \\
\text { devem estar abrangidas por } \\
\text { processos de democratiza- } \\
\text { ção, incluindo os média. }\end{array}$ & $\begin{array}{l}\text { O cidadão enquan- } \\
\text { to pleno ator no } \\
\text { processo deliberativo. }\end{array}$ & $\begin{array}{l}\text { Perspectiva democrática radi- } \\
\text { cal; cidadãos integrando pro- } \\
\text { cesso de decisão; funciona- } \\
\text { mento 'de baixo para cima'. }\end{array}$ \\
\hline
\end{tabular}

Tabela 1: Perspectivas sobre participação dos usuários e audiências implícitas

Esta operacionalização abre caminho às seguintes questões de investigação:

QI 1: Como foram organizados os processos de tomada de decisão nos novos tratados de radiodifusão?

Q12: Que imagem de 'audiência implícita' pode ser reconhecida em ambos os processo de decisão - terá a audiência sido entendida como consumidora ou como cidadã?

QI 3: Estarão as ideias sobre audiência implícita refletidas nas emendas que deram corpo à nova estrutura regulatória do serviço público de média? 


\section{ObSERVAÇÕES E ANÁLISE}

A ideia da teoria democrática e da participação dos cidadãos no discurso público está profundamente enraizada no quadro jurídico do serviço público de média na Alemanha. A grande importância do SPM para a formação de opinião e para toda a sociedade tem sido atestada e confirmada pelo Tribunal Constitucional Federal em vários momentos desde a sua primeira decisão de 1961. De acordo com esta entidade o SPM é obrigado a seguir um princípio de utilidade pública, centrado num claro mandato educativo. O SPM é uma referência para o debate público e deve fornecer serviços fundamentais na linha do que é designado por Reithian-Trinity: informação, educação e entretenimento (Enli, 2008, p. 106). O mandato normativo do SPM é permitir que todos os cidadãos formem opinião em liberdade. Em contraste, a radiodifusão comercial não está equipada com um mandato comparável. Para cumprir a sua missão, o SPM é financiado por taxas de radiodifusão, que atualmente totalizam mais de oito mil milhões de euros, com as quais se gerem 22 diferentes estações de televisão analógica e digital e 60 estações de rádio em toda a Alemanha (Beitragsservice, 2014, p. 41).

Os objetivos normativos têm, no entanto, sido desafiados. O serviço público de radiodifusão opera num ambiente de comunicação pluralizado e em rápida mutação. $\mathrm{Na}$ Alemanha, o SPM tem sido desafiada por mudanças políticas, tecnológicas e demográficas, pela digitalização e convergência, ao mesmo tempo que acontece uma grande mudança no comportamento da audiência, que troca o registo de consumidor pelo de prosumers. (losifidis, 2010, p. 1; Jakubowicz, 2010; Lowe, 2007)5. Grupos ativos da sociedade afirmam, porém, ser ainda ouvidos enquanto consumidores, como destacou Daskal (2016). Nas secções a seguir, são explorados dois casos de inclusão de cidadãos na regulamentação e planeamento estratégico.

\section{A decisão do Tribunal Constitucional Federal sobre a ZDF}

$\mathrm{Na}$ dieta mediática dos alemães a TV é ainda o principal meio com a mais vasta abrangência. Para $86 \%$ dos consumidores médios alemães acima de 14 anos, a TV é o meio preferido para aceder a informação, seguida pela rádio (79\%) e pela internet (43\%) (ARD \& ZDF, 2011, p. 16). Um estudo representativo com comparação intermediária indicou que 68,6\% da população alemã (com mais de 14 anos) depende da TV pública e que 66,5\% depende da rádio pública para a sua informação (Hasebrink \& Schmidt, 2012, p. 36). No ano de 2015 isto representava uma média de 207 minutos de consumo diário de televisão, 173 minutos de consumo de rádio e 107 minutos de uso da internet. Para os jovens, com idades entre os 14 e os 29 anos, o meio preferido é a internet (173 minutos diários) seguida da TV (144 minutos diários) (Engel \& Breunig, 2015, p. 312).

A ZDF é a segunda maior rede de SPM da Alemanha, com sede no estado federal ocidental da Renânia-Palatinado. É uma emissora de serviço público de alcance nacional

\footnotetext{
${ }_{5}^{5}$ Num ambiente digital a audiência pode aceder a ferramentas e espaços para produzir os seus próprios conteúdos. Pode, por exemplo, comentar o conteúdo da TV através de redes sociais ou websites independentes com o auxílio de um segundo ecrã. Estes usuários ativos são descritos como 'prosumers' ou 'produsers'.
} 
apenas com televisão. A ZDF e nove emissoras sob a égide da ARD participam conjuntamente em operações de programas com a Suíça e a Áustria (3sat) e com a França (Arte). Em 2015 a ZDF teve a mais alta quota de mercado na Alemanha pelo quarto ano consecutivo.

O ponto de partida para a ação judicial no Tribunal Constitucional Federal foi o impedimento de reeleição do editor-chefe da ZDF em 2009, após suspeitas de intervenção do primeiro-ministro conservador Roland Koch, membro da União Cristã-Democrática (CDU) e à data dos factos vice-presidente do conselho de radiodifusão da ZDF. O editor-chefe da ZDF teve que renunciar e foi substituído por Peter Frey, presumivelmente mais de acordo com a política do partido conservador. No entanto, Renânia-Palatinado e Hamburgo assumiram o processo eleitoral como ilegal e decidiram exigir ao Tribunal Constitucional uma revisão judicial do caso. O ponto principal da acusação foi o assumido poder decisivo dos políticos nos órgãos da ZDF em virtude do seu elevado número. De facto, até julho de 2016, o conselho de radiodifusão tinha 77 membros, dos quais pelo menos $44 \%$ eram membros de partidos políticos ou dos governos nacionais ou federais.

Importará referir que o debate sobre a influência política nos órgãos de supervisão faz parte do DNA da ZDF; antes de seu estabelecimento, em 1963, o governo conservador de Konrad Andenauer (CDU) planejou um outro programa (paralelo aos dos radiodifusores sob a égide da $A R D$ ) regulado por uma lei federal e não pelos estados federais. Na altura, o Tribunal Constitucional Federal (naquele que seria o seu primeiro pronunciamento, em 1961) decidiu que a radiodifusão é um bem cultural e que, portanto, necessita de regulação independente pelos estados federais. O que é ainda mais importante, à luz dos acontecimentos recentes, é que o mais alto tribunal recusou também a pretendida influência dominante dos políticos nos órgãos de decisão. Embora a ZDF tenha sido construída como um organismo de radiodifusão de serviço público a partir desta intervenção do Tribunal Federal, o debate sobre a influência dominante da política nos órgãos de supervisão do ZDF tem emergida nas últimas décadas numa base regular (Donsbach \& Mathes, 2000, pp. 486-492; Krotz, 1996).

A não permitida reeleição do editor-chefe da ZDF, Nikolaus Brender, reconhecido pela sua integridade e independência, criou um impulso para esclarecer uma irritação duradoura do conselho ZDF, uma entidade dominada por políticos (conservadores). Assim, na sua $14^{\mathrm{a}}$ sentença de radiodifusão, em março de 2014, o Tribunal Constitucional Federal decidiu a favor do promotor que pediu esclarecimentos sobre se a grande quantidade de políticos no conselho seria uma violação da exigência constitucional do SPM ser distante do Estado. As indicações mais importantes resultantes deste processo são:

1. Por forma a reduzir a influência do Estado, políticos e representantes do governo não podem exceder um terço do total de membros dos conselhos;

2. Representantes dos partidos políticos deixam de ter assento nos conselhos;

3. O trabalho dos conselhos do SPM deve ser transparente, para que a sociedade possa co-controlar a atividade das entidades e o trabalho dos órgãos regulatórios;

4. Os conselhos de radiodifusão têm de ser diversificados e devem adoptar um regime de composição mais dinâmico, por forma a reflectir a 'diversidade de experiências e interesses' da sociedade e a contrariar a cristalização de maiorias de opinião dominante. Isso também inclui pequenos grupos e 
indivíduos que não estão representados nos meios de comunicação, "para que também as perspectivas não coerentemente organizadas possam ser refletidas" (Bundesverfassungsgericht, 2014, s/p).

Se pensarmos em 60 anos de história da SPM na Alemanha, este último ponto, tal como é enunciado, pode ser visto como uma pequena revolução. A composição dos conselhos permaneceu mais ou menos inalterada desde a sua fundação, após a Segunda Guerra Mundial, até 2016. Os grupos sociais, sub-representados ou mais ou menos excluídos nos órgãos de supervisão, como representantes das mulheres, migrantes ou minorias religiosas, devem agora ter o direito de participar. Salienta-se ainda que uma proporção dos representantes dos conselhos deve reflectir os interesses não organizados da sociedade civil, bem como os dos indivíduos, o que é uma novidade dentro do modelo corporativista do sistema de mídia alemão (Hallin \& Mancini, 2004). A exigida composição "dinâmica" do conselho de radiodifusão desafia o actual esquema de representação rígida. Além disso, exige que a igualdade de gênero seja respeitada; um levantamento da liga feminina de jornalistas (Journalistinnenbund, 2012) revelou que em seis dos onze órgãos de supervisão menos de $30 \%$ dos representantes eram do sexo feminino - isso é agora percebido como uma violação da legislação.

$\mathrm{Na}$ perspectiva mais ampla de uma reestruturação do SPM para o século XXI, a decisão pode não ser revolucionária, mas antes pragmática, uma vez que políticos e representantes governamentais não são completamente banidos dos conselhos e ainda podem constituir uma parcela poderosa, não apenas em número mas também em termos de poder qualitativo através de redes informais chamadas "círculos de amizade" (Freundeskreise). Embora tenham também sido criticados pelo mais alto tribunal do país esses círculos influentes não foram tocados pelo legislador, provavelmente porque as redes informais são difíceis de mapear ${ }^{6}$.

\section{AUdiÊNCIAS ENQUANTO ACTORES DA SOCIEDADE CIVIL EM DEBATES SOBRE POLÍTICAS MEDIÁTICAS E REGULAÇÃo DOS MÉDIA}

O mercado de média alemão é aquele que possui a mais alta abrangente e diversificada oferta de transmissão e produção na Europa. No entanto, tal como mencionado acima, a política dos meios de comunicação social parece não consignar atenção especial à sociedade civil. É uma peculiaridade do sistema alemão que embora haja - como referido - uma inspiração histórica no modelo britânico ela não tenha reflexo na existência de uma organização semelhante à Voz do Ouvinte e Telespectador (VLV). A VLV foi fundada em 1983 por Jocelyn Hay e tornou-se um influente grupo de pressão com o objetivo de salvaguardar a independência e a qualidade dos programas da BBC. A VLV luta pela existência de um órgão independente para gestão da taxa de radiodifusão - um conselho que lidere o debate público sobre o financiamento da BBC - uma vez que as negociações mais recentes sobre a instituição decorreram apenas no âmbito do governo e longe do envolvimento das audiências (VLV, 2015).

${ }^{6}$ Discutimos os aspectos particulares da dinâmica e da diversidade no novo enquadramento regulatório da ZDF num outro trabalho - ver Horz (2016). 
Na Alemanha, a implementação de uma nova taxa de radiodifusão no ano de 2013 - um pagamento 'por cidadão' ou 'imposto por domicílio' em vez do antigo pagamento por dispositivo - criou um impulso para um debate público mais amplo sobre questões de política dos média. Alguns usuários rejeitaram as novas taxas ou até mesmo o SPM por completo e surgiram inúmeros grupos de pressão com o objetivo de contrariar a medida e de questionar a existência de um SPM.

Os grupos de pressão que rejeitam as taxas consideram o novo esquema de financiamento injusto e dizem tratar-se de um imposto (Zwangsabgabe). Ativistas como Remote Control, Iniciative Mediennutzung ohne Zwangsgebühren (Iniciativa para o uso de média sem cobrança compulsória) ou Online-Boykott questionam-se sobre a obrigatoriedade de pagar por serviços básicos quando podem dispor de uma enorme variedade de conteúdos mediáticos. De acordo com suas próprias contas, as diversas petições on-line organizaram cerca de 800 mil assinaturas contra a taxa domiciliar. Os ativistas da Remote Control, combinando princípios construtivistas com seu boicote, organizaram mais de seis mil pessoas que, em conjunto, deixaram de pagar ao Estado mais de 2,5 milhões de euros em licenças. Exigiam ser recompensados pela taxa com um serviço público de média que não mais ignorasse o debate público: "suspendemos os nossos pagamentos para negociar a forma como são gastas as taxas. Exigimos um cálculo socialmente aceitável do montante. Exigimos transparência política e económica. O serviço público de média precisa de ser tão plural como os seus usuários" (Remote-Control, 2013, s/p)7.

A Online-Boykott descreve-se como a "maior plataforma orientada para o finan-

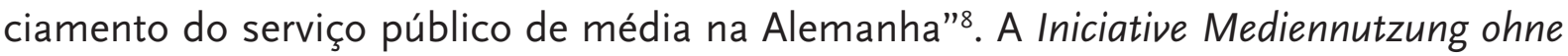
Zwangsgebühren lançou uma petição aberta ao público e recolheu mais de 12 mil assinaturas, segundo os seus próprios relatos ${ }^{9}$. Não é, no entanto, possível avaliar a credibilidade deste números nem se os ativistas emergiram de forma espontânea a partir da sociedade civil ou se são emanações de grupos de pressão neo-liberais como, por exemplo, o GEZ-Boykott. Esta campanha, em particular, foi lançada pelo Instituto Prometeu, que tem uma clara agenda de oposição ao financiamento público dos média e que tem ligações ao partido FDP, o moderador de um debate anti-SPM de que falaremos mais adiante no texto ${ }^{10}$.

A Conferência Permanente da Audiência do SPM (Ständige Publikumskonferenz der öffentlich-rechtlichen Medien e.V.) é uma associação que está principalmente focada na crítica a conteúdos de média e na apresentação de queixas formais mas subscreve também a leitura de que o SPM tem um comportamento altivo e distante os telespectadores e ouvintes (Kleinsteuber, 2011; Wolf, 2015).

Embora seja necessária mais investigação em profundidade sobre o tema percebe-se nestes exemplos a emergência de uma orientação com foco no usuário como

\footnotetext{
7 Retirado de http://www.zahlungsstreik.net/.

${ }^{8}$ Retirado de http://online-boykott.de/de/buergerwehr/146-kontrolle-ist-besser-aber-wer-kontrolliert-die-kontrolleure.

9 Retirado de http://www.mediennutzung-ohne-zwangsgebuehren.de/index.php/petition-unterschriftensammlung; https://www.openpetition.de/petition/online/ard-zdf-so-gez-nicht-weiter-zahlungszwang-stop-rundfunkreform-jetzt.

${ }^{10}$ Retirado de http://prometheusinstitut.de/uber-uns/.
} 
consumidor (taxa de radiodifusão, crítica de conteúdos). Iniciativas de participação cívica focadas em problemas específicos e exigindo mudanças estruturais e melhores oportunidades de participação na governança dos média parecem, no entanto, ser raras. A Iniciativa SPM (Initiativkreis öffentlich-rechtlicher Rundfunk, Köln e.V.), que apareceu em 1994 e tem sido ativa desde então, é um fenómeno bastante regional, centrado em Colónia, junto a uma grande estação emissora, a WDR. Um grupo ativista de "baixo para cima", a Associação para a Criação de Conselhos de Audiência (Initiative zur Etablierung von Publikumsräten) empenha-se no aumento de oportunidades de inclusão da audiência em processos de debate sobre políticas de média e em processos de decisão sobre SPM. Estes grupos da sociedade civil são sobretudo compostos por estudiosos de média e comunicação, ex-funcionários do SPM e ouvintes e espectadores individuais que têm um interesse particular num serviço público de qualidade. O debate académico sobre a inclusão de público na discussão de políticas de média e na governança do serviço público de radiodifusão tem sido realizado há mais de trinta anos na Alemanha, desde a liberalização do mercado da radiodifusão; o que é novo, no entanto, é a recente tentativa de usar o debate sobre a reestruturação dos conselhos de radiodifusão como um ponto de partida para promover um discurso de 'baixo para cima' sobre questões de políticas dos média.

$\mathrm{Na}$ Alemanha, os conselhos de radiodifusão devem representar a audiência em geral, uma missão que foi recentemente confirmada pelo regulador e consignada no $17^{\circ}$ Tratado para uma radiodifusão interestadual alterada (17. Rundfunkänderungstaatsvertrag, \19a (1), citado em Bundesländer, 2015, p. 6). Confrontados com a questão da participação da audiência, os membros do conselho de radiodifusão e os diretores descrevem os seus papéis como os de defensores ou provedores do público, considerando, portanto, desnecessária qualquer participação adicional. O que se percebe nalguns estudos académicos sobre o tema é que frequentemente essas pessoas consideram-se representantes de suas respectivas organizações e não do público em geral. Em conformidade, o seu trabalho é descrito como não-transparente e elitista (Kleinsteuber, 2011, p. 59).

O que se debate, portanto, é a legitimidade de um sistema representacional dominado apenas por grupos de interesse para decidir sobre e supervisionar o SPM e a sua eventual adaptação a um formato em que a audiência possa tomar parte de forma mais direta e plebiscitária. No que se refere à governança dos meios de comunicação, as audiências como atores da sociedade civil não devem ser responsabilizadas apenas financeiramente, mas também envolvidas nos processos de tomada de decisão (Eilders et al., 2006; Jarren, 2007; Kleinsteuber \& Nehls, 2011; Krotz, 1996). Assim, melhores opções de participação parecem razoáveis, mas precisam de ser consideradas cuidadosamente em face da liberdade de transmissão e da questão de quem é legitimado para falar por outros.

\section{O DEBATE PÚBLICO}

Carpentier (2011a) refere-se à discrepância entre as opções de participação na Internet e o SPM como um paradoxo que é usado em batalhas sobre a definição do que é 
ou não é democrático. Essas batalhas também podem ser observadas no recente debate sobre a emenda do tratado interestadual ZDF. É importante mencionar que esses argumentos devem ser considerados no âmbito de uma controvérsia mais ampla sobre o papel e o propósito do SPM na Alemanha.

Dois tipos de discurso dominaram o debate público durante as negociações sobre o novo quadro regulamentar para a ZDF e outros radiodifusores de SPM, com um deles defendendo o abandono completo do SPM. Trata-se de um discurso influenciado por uma agenda neoliberal e defendido por grupos de interesse que percebem o financiamento público do SPM como uma distorção da concorrência em mercado livre. Grupos de pressão, como a Associação de Radiodifusores Privados e Telemedia (Verband Privater Rundfunk-und Telemedien, VPRT) ou a Associação Federal de Editores Alemães de Jornais (Bundesverband deutscher Zeitungsverleger), que não podem depender do financiamento público, têm um interesse real num mercado mediático liberalizado em contraste comos propósitos do SPM. Grupos como a Associação Federal da Economia Digital apresentam as suas próprias recomendações: que o SPM deve ser prestado por entidades não-financiadas num ambiente totalmente liberalizado (Bundesverband Digitale Wirtschaft, 2015). Numa outra vertente ainda, representantes de uma audiência crítica, bem como representantes de grupos de direita ou cépticos anti-islâmicos como PEGIDA e outros grupos ideológicos, acusam o SPM de uma prestação tendenciosa em termos de informação.

Também os debates políticos foram parcialmente elaborados em torno do argumento da abolição do SPM. O conselho científico do Ministério das Finanças divulgou um relatório técnico, defendendo o fim do financiamento público do SPM; a argumentação baseava-se na ideia de que em vez de modelo de referência o SPM deveria constituir-se como espaço de programação alternativa à disponibilizada pelas emissoras comerciais. O relatório não se referia ao facto de o SPM ter uma proteção legal especial e se consideramos o momento da sua divulgação pública - no meio do processo de negociação sobre um novo quadro regulamentar - pode ser entendido como parte de uma campanha política para influenciar as negociações (Wissenschaftlicher Beirat des Bundesfinanzministeriums, 2014).

O segundo tipo de discurso, apresentado principalmente por estudiosos de comunicação, políticos liberais e profissionais que têm interesse num SPM a funcionar em pleno, centra-se numa crítica qualificada sobre cobertura, supervisão e organização das entidades. Segundo esta visão, o SPM está de acordo com os princípios normativos democráticos e resulta em benefício para um sistema de média pluralista. Defendem-se novos modelos para uma participação mais ampla da sociedade civil na governança dos média em vez das atuais estruturas corporativistas. Esta perspectiva trata basicamente da coletivização do processo de regulação dos média em consonância com os direitos fundamentais (Krieg \& Rhomberg, 2015). 


\section{ORGANIZAÇÃo dOS PROCESSOS DE DECISÃo PARA NOVOS ENQUADRAMENTOS REGULATÓRIOS}

\section{Negociando POlíticas de MÉdia NA RENÂNiA-PALATINAdo, SEDE DA ZDF}

A Renânia-Palatinado, que liderou as negociações a nível nacional, convidou pela primeira vez a audiência a participar numa audição pública através da internet. Desta forma, todos os interessados poderiam contribuir com recomendações para $017^{\circ}$ tratado interestadual (Ministerin für Bundesangelegenheiten, Europa und Medien, 2015). Das 29 declarações recebidas pela chancelaria estadual, 26 vieram de partidos políticos, sindicatos, algumas associações cívicas como organizações LGBTQ, a sociedade humanista e organizações de direitos das mulheres. Além disso, o SPM e até a própria ZDF participaram do processo, bem como outras organizações profissionais de média, associações de produtores de média e da economia digital.

A abertura do debate público indica que audiência implícita é já entendida no seu papel de cidadania. No entanto, a questão em aberto sobre o que deveria ser alterado exigia conhecimentos especializados. Por conseguinte, apenas dois contributos vieram de grupos de audiência "de baixo para cima" (Publikumsrat e Ständige Publikumskonferenz) e apenas uma declaração foi enviada por um cidadão individual. Além disso, a declaração do cidadão individual, o Sr. Wall, não foi inicialmente publicada. O Sr. Wall declarou, numa entrevista com a autora deste artigo (2015), que discutiu o assunto com o governo estadual e que, finalmente, a declaração foi também tornada pública. Este incidente parece dar nota de uma certa ambivalência na postura do regulador ao solicitar a participação da audiência. Os responsáveis pela regulação dos média parecem ainda definir a audiência enquanto cidadão com parâmetros ligados a uma ideia corporativa sobre processos de decisão democrática. Embora as declarações apresentadas sejam publicadas na página online do governo estadual, não há mais comentários. " Mais uma vez, a atenção parece centrar-se nos especificamente informados ou interessados nas declarações e no processo de consulta e não em um debate público mais alargado.

O processo negocial, antes e depois da consulta, foi criticado. Na sequência da apresentação de um primeiro documento de trabalho, em 19 de maio de 2015, grupos da sociedade civil denunciaram o facto de a composição do futuro conselho - de acordo com o projecto - ainda não ser suficientemente independente da influência estatal (Huber, 2015). Políticos como Tabea Rößner (ministra federal e porta-voz do Partido Verde para os média e as indústrias criativas) exigiram mais transparência e um debate público mais amplo. Propôs convocar uma comissão independente que deveria, em primeiro lugar, discutir quem teria legitimidade para representar o público em geral (MP, 2015). No entanto, os primeiro-ministros dos estados federais (Bundesländer) não seguiram esta proposta e decidiram sobre a composição do conselho à porta fechada.

O público foi apenas esporadicamente informado sobre o andamento do processo pelos média, por exemplo, após a convenção dos primeiro-ministros dos 16 estados federais que declarou uma redução de assentos no conselho ZDF de 77 para 60 (Grimberg, 2014). Esta reduzida transparência é particularmente interessante, uma vez que

\footnotetext{
"Retirado de https://www.rlp.de/ar/landesregierung/staatskanzlei/medienpolitik/.
} 
acontece depois de ter havido uma sensibilização generalizada para o tema e também porque interfere com o ponto central da decisão do Tribunal Constitucional Federal.

O Tribunal Constitucional Federal exigiu uma redução de políticos para não mais de um terço do total de membros, o que veio a ter reflexo no novo tratado. Assim, 20 membros dos novos conselhos são funcionários ou representantes do governo. Os restantes 40 representantes são divididos em dois subgrupos. O primeiro agrega em grupos de interesse socialmente relevantes, como igrejas, sindicatos, organizações de empregadores e outros que já tinham assento na composição anterior. O segundo subgrupo tem 16 representantes, cabendo a cada Estado nomear uma minoria específica, como jovens, migrantes, muçulmanos, etc. A composição deste grupo de 'pequenos grupos' será auditada após dois períodos legislativos (oito anos).

É realmente positivo que, pela primeira vez desde a concepção do SPM, seja agora concedido lugar às minorias nestes órgãos. No novo sistema cada grupo minoritário participantes não necessitará mais de negociar em separado as suas exigências específicas relativas ao SPM, passando agora isso a fazer parte do processo global. Em qualquer caso, a orientação deste grupo estará ainda longe do que foi enfatizado pelo Tribunal Constitucional, sobretudo no que concerne às minorias culturais e religiosas. Apenas seis das onze estações de SPM na Alemanha forneceram, até agora, um lugar para representantes de migrantes, por exemplo. Além disso, apenas duas estações de SPM reservam um lugar para os muçulmanos nos órgãos de supervisão, embora o Islão seja a segunda maior religião na Alemanha depois do Cristianismo (Horz, 2016).

Um exame mais aprofundado da alteração revela outros aspectos problemáticos. Em primeiro lugar, observa-se uma hierarquia entre crenças religiosas; quatro representantes cristãos e um representante judaico pertencem aos grupos com assentos fixos, ao passo que os representantes muçulmanos pertencem ao grupo dos "pequenos grupos" que podem ser facilmente excluído após a primeira auditoria. Os cristãos representam cerca de $60 \%$ da sociedade, a minoria judaica é estimada em menos de 200 mil pessoas e cerca de quatro a seis milhões de muçulmanos vivem na Alemanha. No entanto, o Islão não tem na Alemanha o mesmo estatuto corporativo do Cristianismo. Isso assume especial importância no que diz respeito ao direito de transmissão de terceiros, que permite às entidades corporativas representadas nos órgãos influenciar a programação. Assim, a alteração do novo quadro regulamentar para a ZDF reflecte mal a "super-diversidade" da sociedade alemã.

Não estarão igualmente representados grupos importantes como o movimento de paz ou a Attac (Associação para a Tributação das Transacções Financeiras e para a Acção Cidadã, rede de alter-globalistas, originária da França). Poderá, assim, concluir-se que a composição parece ser arbitrária. Além disso, a avaliação da configuração destes grupos apenas após dois períodos legislativos (oito anos) parece demasiado demorada para um processo que deveria serm mais dinâmico. Grupos da sociedade civil e indivíduos interessados - com ideias inovadoras e potenciais benefícios culturais - permanecem mais ou menos excluídos. A exigência genérica do Tribunal Constitucional Federal sobre a necessidade de entender a audiência enquanto cidadã, dando também a indivíduos e 
a interesses não organizados a oportunidade de participar nos conselhos, continua a ser um problema.

\section{Negociando políticas dos média na RenÂNia do Norte-Westefália, SEde Da WDR}

A WDR é uma emissora regional com alcance nacional e é a maior emissora de serviço público sob a égide da ARD. De acordo com a decisão do Tribunal Constitucional Federal, a Renânia do Norte-Westefália, sede da WDR, também teve que rever o seu enquadramento legal para o SPM, o que resultou no novo Tratado WDR aprovado em 2 de fevereiro de 2016. Como na Renânia-Palatinado, o governo do estado decidiu lançar um processo de audição pública. No entanto, em contraste com o sucedido na Renânia-Palatinado, o método de consulta pública desenrolou-se de forma ligeiramente diferente.

O processo desenrolou-se com o auxílio de um questionário online com perguntas fáceis e acessíveis relacionadas com a vida quotidiana dos telespectadores e ouvintes. Esteve disponível entre 19 de fevereiro e 19 de março de 2015 (Presseinformation, 2015). A consulta online envolvia 20 perguntas, em torno de questões sobre políticas de média, programação e o papel da WDR como uma instituição. Aparentemente dava corpo a uma indagação sobre o valor público da WDR a partir da perspectiva dos cidadãos.

De acordo com a ministra para os meios de comunicação social, Angelika Schwall-Düren, o questionário online recebeu "feedback esmagador" (Ministerin, Startpage da Consulta Online, 2015); cerca de 1200 comentários e mais de 1700 apreciações foram validadas. Além disso, 13 declarações chegaram ao governo estadual, das quais sete foram enviadas por usuários individuais da WDR e duas por grupos de audiência de "baixo para cima". Surpreendentemente, muitas das declarações, visíveis na homepage especialmente criada para o processo de consulta, apresentavam fundamentação sólida. A pergunta número oito (sobre a composição do conselho de radiodifusão) recebeu 59 comentários. O comentário número um, por exemplo, diz que a composição do conseIho está ultrapassada e não reflete mais a sociedade pluralista. O comentário número quatro pergunta por que razão os muçulmanos são excluídos da participação, enquanto que o comentário número cinco rejeita totalmente representantes de grupos religiosos no conselho. A maioria dos comentários é anónima, o que torna difícil analisar a sua origem - sociedade civil ou especialistas, profissionais de média, funcionários da WDR ou grupos de interesse. Além disso, também não é possível dizer se os comentadores fizeram login várias vezes para publicar de forma repetida sobre o mesmo problema.

As respostas e as declarações refletem um entendimento mais participativo dos órgãos da WDR. Na alteração do Tratado WDR ficou estabelecido que nove dos 58 assentos serão publicamente eleitos - sete para a estrutura de governança e dois para o conselho de radiodifusão da WDR. O legislador da Renânia do Norte-Westefália cumpriu em parte a exigência do Tribunal Constitucional Federal de maior transparência, de maior diversidade e de impedir a cristalização das entidades reguladoras. Pela primeira vez na Alemanha estruturas de governo do SPM abriam-se a pedidos de adesão da sociedade civil e indivíduos. 


\section{NOTAS CONCLUSIVAS}

O Tribunal Constitucional Federal exigiu um esquema complexo de representação baseado na teoria democrática. Importaria alcançar uma solução que respeitasse os direitos dos grupos, bem como os interesses individuais, a fim de reforçar a legitimidade pública do SPM - uma ideia que refletia também o debate acadêmico (Kleinsteuber, 2011, p. 74).

O caso das negociações de tratado interestadual da ZDF indica que nem o legislador nem a sociedade civil seguiram uma visão implícita da audiência enquanto cidadã. Em vez disso, o público foi mais ou menos excluído do processo de tomada de decisão. A consulta aberta criou apenas uma pequena janela de oportunidade para a participação nas decisões sobre a futura composição do conselho da ZDF. As declarações apresentadas ao tratado interestadual da ZDF sugerem que a abordagem da consulta podem ter criado um problema. A consulta alcançou, de forma genérica, os atores organizados e bem informados mas não teve grande eco entre públicos mais amplos da sociedade civil, constituindo-se assim como um processo bastante elitista.

A Renânia do Norte-Westefália também decidiu lançar uma consulta aberta. Em contraste com a Renânia-Palatinado, abordou o público com um questionário online fácil e acessível. As perguntas orientaram o público para importantes questões de políticas dos média, o que facilitou as tomadas de posição. O número encorajador de comentários relacionados com o Tratado WDR sugere que as políticas dos média podem ser uma questão interessante para audiências ativas quando entendidas no seu papel de cidadania. A própria consulta online da WDR criou o potencial para fazer evoluir o debate sobre as políticas dos média. Podemos ainda assumir que o governo da Renânia do Norte-Westefália respeitou parcialmente os comentários dos usuários sobre a necessidade de diversificar a composição dos órgãos de regulação. A inovadora possibilidade de se apresentarem candidaturas a lugares nos conselhos da WDR pode ser um ponto de partida para uma estrutura participativa que ultrapasse o modelo corporativista de gestão tradicional do SPM.

Análise de estudos anteriores sobre a tendência da sociedade civil para se envolver mais em debates de crítica dos média do que em debates sobre políticas dos média precisa de ser reexaminada.

Novos estudos necessitam de prestar atenção à imagem implícita da audiência nos enquadramentos de regulação dos média. Além disso, mais trabalho deverá ser feito sobre a autopercepção e as formas de diálogo entre cidadãos e SPM por forma a melhor contribuir para o entendimento da ideia de audiência cidadã na governança dos média.

\section{REFERÊNCIAS BIBLIOGRÁFICAS}

ARD, ZDF, Deutschlandradio Beitragsservice (2014). Geschäftsbericht 2014. Retirado de https://www. rundfunkbeitrag.de/e175/e1691/Geschaeftsbericht_2014.pdf.

Bundesländer (Ed.) (2015). Siebzehnter Staatsvertrag zur Änderung rundfunkrechtlicher Staatsverträge (17. Rundfunkänderungsstaatsvertrag). Retirado de https://www.rlp.de/fileadmin/rlp-stk/pdf-Dateien/ Medienpolitik/17__RaeStV.pdf. 
Carpentier, N. (2011a) Media and participation: A site of ideological-democratic struggle. Bristol: Intellect.

Carpentier, N. (2011b). The concept of participation: If they have access and interact, do they really participate? Communication Management Quarterly VI (21), 13-36.

Carpentier, N. (2015). Differentiating between access, interaction and participation. Conjunctions: Transdisciplinary Journal of Cultural Participation, 2(2), 8-28.

D'Arcy, J. (1977). Direct broadcast satellites and the right of man to communicate. In L.S. Harms, J. Richstad \& K. Kie (Eds.), The Right to Communicate: Collected Papers (pp. 1-9). Honolulu: Social Sciences and Linguistics Institute, University of Hawaii at Manoa; distributed by University Press of Hawaii.

Daskal, E. (2016). My voice needs to be heard: Cultural challengers in the regulatory arena. International Journal of Communication, 10, 786-804.

Donsbach, W. \& Mathes, R. (2000). Rundfunk. In E. Noelle-Neumann, W. Schulz \& J. Wilke (Eds.), Publizistik, Massenkommunikation: Fischer Lexikon (pp. 475-518). Frankfurt a.M.: Fischer.

Eilders, C., Hasebrink, U. \& Herzog, A. (2006). Das aktive Publikum. Instituionalisierung zivilgesellschaftlicher Kontrolle des Fernsehens auf europäischer Ebene. In W. Langenbucher \& M. Latzer (Eds.), Europäische Öffentlichkeit und medialer Wandel (pp. 330-351). Wiesbaden: VS Verlag.

Engel, B. \& Breunig, C. (2015). Massenkommunikation 2015: Mediennutzung im Intermediavergleich: Ergebnisse der ARD/ZDF Langzeitstudie. Media Perspektiven, 7-8, 310-322. Retirado de http:// www.ard-werbung.de/media-perspektiven/publikationen/fachzeitschrift/2015/artikel/ massenkommunikation-2015-mediennutzung-im-intermediavergleich/.

EBU (Eds.) (2014). Vision 2020: Connecting to a Networked Society. Continuous Improvement of Trust and Return-on-Society. Retirado de https://www3.ebu.ch/files/live/sites/ebu/files/Publications/ EBU-Vision2O2O-Full_report_EN.pdf.

Enli, G. S. (2008). Redefining Public Service Broadcasting: Multi-platform-participation. Convergence: The International Journal of Research into New Media Technologies, 14(1), 105-120.

Foster, R. (2007). Future Broadcasting Regulation: An independent Report by Robin Foster commissioned by the Department for Culture, Media and Sport. Retirado de http://www.refoster.co.uk/ FutureBroadcastingRegulation.pdf.

Habermas, J. (1990 [1962]). Strukturwandel der Öffentlichkeit. Frankfurt a.M.: Suhrkamp.

Hallin, D.C. \& Mancini, P. (2004). Comparing media systems: Three models of media and politics. Cambridge: Cambridge University Press.

Hasebrink, U. (2011). Giving the audience a voice: The role of research in making media regulation more responsive to the needs of the audience. Journal of Information Policy, 1, 321-336. Retirado de http://www. jstor.org/stable/10.5325/jinfopoli.1.2011.0321.

Hasebrink, U. \& Schmidt, J.H. (2012). Informationsrepertoires der deutschen Bevölkerung: Konzept für eine regelmäßig durchzuführende bevölkerungsrepresentative Befragung im Rahmen des Vorhabens "Erfassung und Darstellung der Medien- und Meinungsvielfalt in Deutschland". Arbeitspapiere des HansBredow-Instituts, 24. Retirado de https://www.hans-bredow-institut.de/webfm_send/657.

Horz, C. (2016). The politics of diversity and Public Service Media in Germany. In C. Richter, I. Dupuis \& S. Averbeck-Lietz (Eds.), Diversity in Transcultural and International Communication (pp. 35-65). Münster: Lit-Verlag. 
Jakubowicz, K. (2008). Participation and partnership: A Copernican revolution to re-engineer Public Service Media for the 21st century. Keynote RIPE@2008. Retirado de http://ripeat.org/wp-content/ uploads/2010/03/Jakubowicz.pdf.

Jakubowicz, K. (2010). PSB 3.0: Reinventing European PSB. In P. Iosifidis (Ed.), Reinventing Public Service Communication: European Broadcasters and beyond (pp. 9-22). Basingstoke: Macmillan,.

Jarren, O. (2007). Verantwortungskultur durch Media Governance: Plädoyer für einen Paradigmenwechsel in der Medienpolitik. Funkkorrespondenz, 6, 3-12.

Kleinsteuber, H. (2011). Regulierung und governance: Zivilgesellschaft in die medienpolitik. In H. J. Kleinsteuber \& S. Nehis (Eds.), Media Governance in Europa: Regulierung - Partizipation Mitbestimmung (pp. 57-89). Wiesbaden: VS.

Krieg, J. \& Rhomberg, M. (2015). Öffentliches Gut. epd medien, 19. Retirado de http://www.epd.de/fachdienst/ fachdienst-medien/schwerpunktartikel/\%C3\%B6ffentliches-gut.

Krotz, F. (1996). Zur konzeption einer stiftung medientest. Rundfunk und Fernsehen, 2, 214-229.

Livingstone, S. \& Lunt, P. (2011). The implied audience of communications policy making: Regulating media in the interest of citizens and consumers. In Nightingale, Virginia (Ed.), The Handbook of Media Audiences (pp. 169-189). Oxford: Whiley-Blackwell Publishing.

Lowe, G. F. (2007). The role of Public Service Media for widening individual participation in European democracy. Council of Europe's Group of Specialists on Public Service Media in the information society: Strasbourg. Retirado de https://rm.coe.int/CoERMPublicCommonSearchServices/DisplayDCTMConten t?documentld=0900001680483b33.

Mclver, J.M. Jr., Birdsall, F.B. \& Rasmussen, M. (2003). The Internet and the right to communicate. First Monday: Peer-Reviewed journal on the internet, 8(12). Retirado de http://firstmonday.org/article/ view/1102/1022.

Puppis, M., d'Haenens, L. \& Saeys, F. (2007). Broadcasting policy and regulatory choices. In F. Saeys \& L. d' Haenens (Eds.), Western Broadcast Models: Structure, Conduct and Performance (pp. 61-78). Berlin, NY: Mouton.

Webster, J. G. \& Phalen, P. F. (1994). Victim, consumer, or commodity? Audience models in Communication Policy. In J.S. Ettema \& D. C.Whitney (Eds.), Audiencemaking: How the Media Create the Audience (pp. 19-37). London: Sage.

Weichert, S.A. (2005, 4 de julho). Stiftung medientest. Die stimme des publikums. Medienheft. Retirado de http://www.medienheft.ch/kritik/bibliothek/k24_WeichertStephanAlexander.html.

Wolf, F. (2015). Wir sind das publikum! Autoritätsverlust der medien und zwang zum dialog. Otto-BrennerStiftung: Frankfurt.

\section{OUTRAS REFERÊNCIAS}

ARD \& ZDF Medienkommission (2011). Migranten und Medien. Neue Erkenntnisse über Medienutzung, Erwartungen und Einstellungen von Menschen mit Migrationshintergrund in Deutschland. [sem informação adicional].

Bundesverfassungsgericht (2014). Entscheidung zum ZDF Staatsvertrag. Retirado de http://www. bundesverfassungsgericht.de/SharedDocs/Entscheidungen/DE/2014/03/fs20140325_1bvfooo111.html. 
European Regulators Group for Audiovisual Media Services (ERGA) (2016). Statement of the European Regulators Group for Audiovisual Media Services (ERGA) on the Necessity of Independent Media. Retirado de https://ec.europa.eu/digital-agenda/en/news/ statement-european-regulators-group-audiovisual-media-services-erga-necessity-independent-media.

Grimberg, S. (2014). Parteienstreit ums ZDF. Retirado de http://www.ndr.de/fernsehen/sendungen/zapp/ blog/Parteienstreit-ums-ZDF,zdffernsehratıo4.html.

Horz, C. \& Schiffer, S. (2014). Erlanger Erklärung. Retirado de http://www.publikumsrat.de/ueber-uns/ erlanger-erklaerung/.

Huber, J. (2015). Neuer staatsvertrag: Die politik regiert weiter mit. Retirado de http://www.tagesspiegel.de/ medien/neuer-zdf-staatsvertrag-die-politik-regiert-weiter-mit/11442026.html.

Journalistinnenbund e.V. (2012). MDR Rundfunkrat: Letzter Platz im Quotenranking. Retirado de https:// www.journalistinnen.de/journalistinnenbund/ueber-uns/der-verband/meldungen/items/mdrrundfunkrat-von-der-frauenquote-peinlich-weit-entfernt.html.

Medienkorrespondenz (2015). Länderchefs einigen sich auf ZDF-Staatsvertragsnovelle. Retirado de http:// www.medienkorrespondenz.de/politik/artikel/laenderchefs-einigen-sich-auf-zdf-staatsvertragsnovelle. html.

Presseinformation der Ministerin für Bundesangelegenheiten, Europa und Medien (2015). Retirado de http://www.mbem.nrw.de/pressemitteilungen/ ministerin-schwall-dueren-startet-online-konsultation-zum-neuen-wdr-gesetz-16560/.

Schweigert, C., Dittes, S. \& Springer, B. (2011). Die protestbewegung gegen Stuttgart 21. Eine qualitative analyse der mobilisierungsmechanismen und framingstrukturen. (The protest movement against the construction Project "Stuttgart 21". A qualitative case study). Retirado de https://publikationen.unituebingen.de/xmlui/handle/10900/47876.

Ver.di (2014). ZDF: Nach dem Urteil von Karlsruhe. Retirado de https://dju.verdi.de/ueber-uns/ nachrichten/++co++b2978674-ecde-11e3-9f68-525400248a66.

Ver.di (2014). Mitbestimmung und Transparenz im öffentlich-rechtlichen Rundfunk. Retirado de https://medien-kunst-industrie.verdi.de/service/ veranstaltungen/++co++9729b75c-23bd-11e4-acao-525400248a66.

Ver.di (2015). Der ÖRR unter Druck. Retirado de http://rundfunk.verdi.de/service/ veranstaltungen/++co++37dbad14-ce44-11e4-b8d6-525400438ccf.

VLV (2016). VLV Calls for Independent Licence Fee Body. Retirado de http://www.vlv.org.uk/vlv-news/newbody-for-licence-fee.html.

WDR (2016). Bewerbung Für den Rundfunkrat. Retirado de http://www1.wdr.de/unternehmen/der-wdr/ gremien/rundfunkrat/ausschreibung102.html.

\section{NOTA BIOGRÁFICA}

Christine Horz é uma investigadora de pós-doutoramento e docente do Instituto de Estudos de Média (IfM) da Universidade de Bochum, na Alemanha. A sua investigação incide sobre os média e as migrações e sobre a participação da sociedade civil na governação dos média. É atualmente co-editora do Global Media Journal-DE para a 
Comunicação Internacional e Intercultural (globalmediajournal.de) e gere uma iniciativa para participação da audiência no debate sobre políticas e governação dos média, Publikumsrat (www.publikumsrat.de).

Email: Christine.Horz@rub.de

Ruhr-Universität Bochum

Institut für Medienwissenschaft, Room: GA 2/141

Universitätsstr. 150

44780 Bochum, Alemanha

* Submetido: 07-03-2016

*Aceite: 14-04-2016 